\title{
ANOMALOUS RELATION OF LUMBAR VESSELS TO THE LEFT KIDNEY - ITS DEVELOPMENTAL \& CLINICAL SIGNIFICANCE
}

Chimmalgi $\mathrm{M}^{1}$, Raju G², Vilasini Sundaresan³, Anil Kumar KV", Manoj Kumar5, Chandrakumari ${ }^{6}$, Subhadra MS 7 , Devi Jaqnsirani D ${ }^{8}$

\section{HOW TO CITE THIS ARTICLE:}

Chimmalgi M, Raju G, Vilasini Sundaresan, Anil Kumar KV, Manoj Kumar, Chandrakumari K, Subhadra MS, Devi Jaqnsirani D. "Anomalous relation of lumbar vessels to the left kidney - its developmental \& clinical significance". Journal of Evolution of Medical and Dental Sciences 2013; Vol2, Issue 29, July 22; Page: 54115416.

ABSTRACT: Lumbar vessels are usually four in number on each side, the veins drain into the inferior vena cava and arteries arise as dorsal branches of the abdominal aorta. The arteries supply the posterior abdominal wall and spinal cord. The veins drain the abdominal wall and vertebral venous plexus. Both travel behind the psoas major muscle, posterior to the kidneys. During routine dissection for the undergraduate students, in two cases we found a left lumbar vein coursing anterior to the left kidney, draining into the anterior aspect of the left renal vein. In one of these cases, a left lumbar artery accompanied the lumbar vein. Developmentally, the vertical segment of the lumbar vein is perhaps the persisting posterior cardinal vein and the horizontal segment crossing the anterior aspect of the left kidney the persisting left postsubcardinal anastomosis anterior to the mesonephros. Clinically, the knowledge of this variation is important not only for the radiologist in imaging of the renal veins but also for the surgeons dealing with this area, specifically for the live donor left kidney nephrectomy using the retroperitoneal approach.

KEYWORDS: Lumbar vein, Lumbar artery, Aberrant Renal artery, Renal vein, Testicular vein, Ovarian vein, Suprarenal vein

INTRODUCTION: In early embryonic period, angiogenesis and vasculogenesis occur in a diffuse pattern. The process of selection and persistence of definitive adult vessels, however, is fairly constant. Occasionally, an unusual vessel persists or a normal vessel disappears, resulting in vascular variations.

Lumbar arteries, usually four on each side, arise as dorsal branches of abdominal aorta. They run posterolaterally in the substance of psoas major muscle posterior to the sympathetic trunk; then cross the quadratus lumborum and at its lateral border pierce the aponeurosis of transverse abdominis to continue between transverse abdominis and internal oblique muscle.

Four pairs of lumbar veins drain the abdominal wall along with the parietal peritoneum and vertebral venous plexuses. Third and fourth veins are more consistent and drain into the inferior vena cava. First and second lumbar veins vary in their termination and, end separately or joined together to form a common trunk (Standring et al). They drain either into inferior vena cava, lumbar azygos vein or ascending lumbar vein. According to Hollinshead, one of the upper lumbar veins of the left side routinely opens into the left renal vein.

We are reporting two cases in which a lumbar vein had an unusual course and termination on the left side and in one of these cases, was accompanied by a lumbar artery.

\section{Case I (Fig. 1)}

During routine dissection, a left lumbar vein was found to be draining into the left renal vein in a 56 year old male cadaver. The vein was initially found to be ascending vertically along 
the posterior abdominal wall in a plane lateral to the left kidney. At the level of the hilum of the left kidney, it turned medially and continued on the anterior surface of the left kidney. Crossing anterior to the hilum it terminated into the left renal vein close to its upper margin on the anterior aspect, lateral to the openings of left suprarenal and left testicular veins.

It was also observed in this case that the left kidney was supplied by two aberrant renal arteries in addition to the regular renal artery at the hilum. The superior aberrant artery - a branch of the abdominal aorta at the level of celiac trunk - entered the kidney on the anterior aspect of the upper pole (superior polar artery). The inferior aberrant artery - a branch of the abdominal aorta $1 \mathrm{~cm}$ proximal to the origin of inferior mesenteric artery - ascended upwards and entered the kidney through the lower part of the hilum.

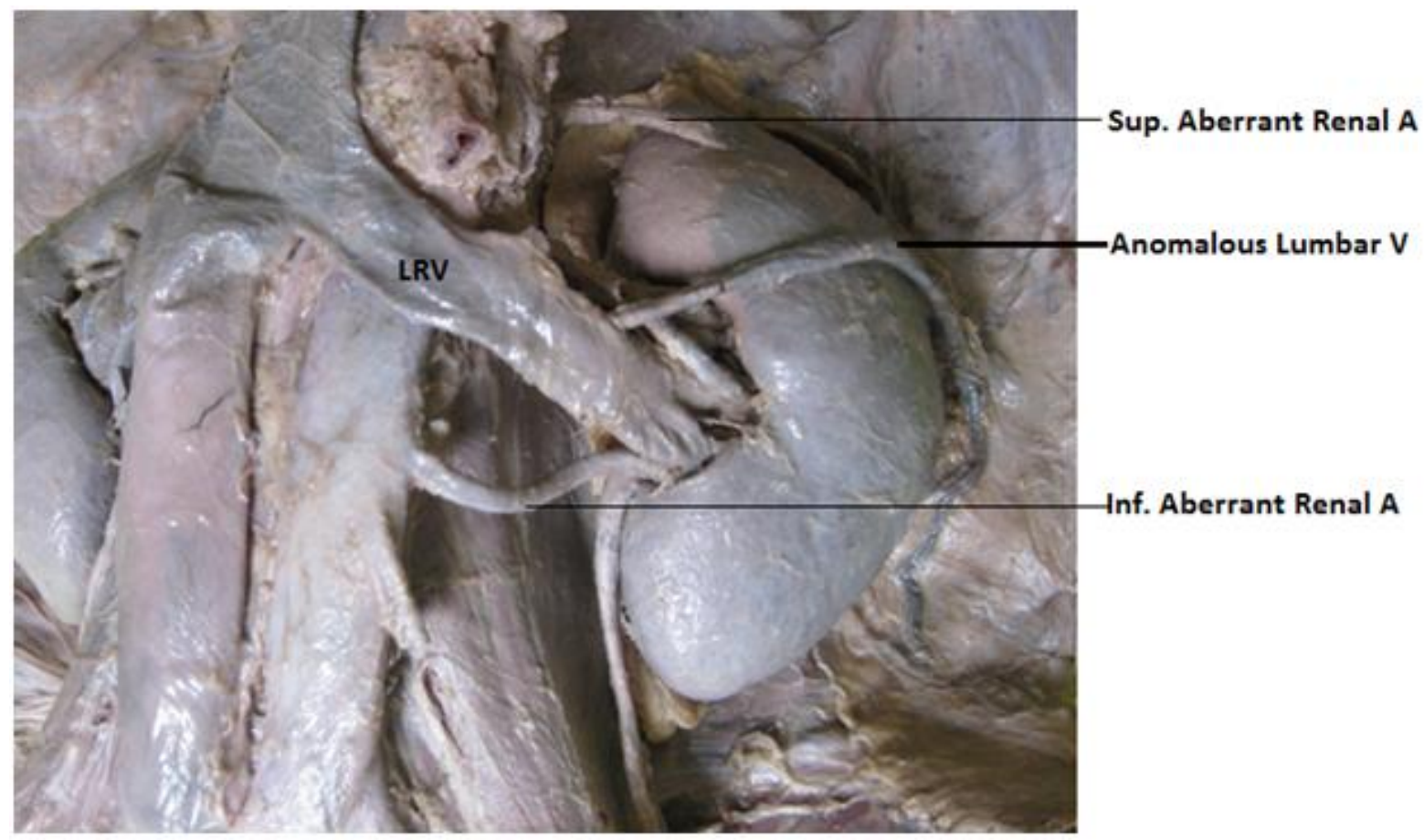

Fig1. Anomalous left lumbar vein coursing anterior to the left kidney \& terminating into left renal vein.

\section{Case II (Fig. 2)}

In a 50 year old female cadaver, it was observed that a pair of lumbar vessels was crossing the anterior surface of the left kidney at the level of its hilum.

Left lumbar vein initially ascended along the posterior abdominal wall lateral to the left kidney, turned medially at the level of the hilum of the left kidney to cross its anterior surface, finally draining into the anterior aspect of the left renal vein, lateral to the openings of left suprarenal and left ovarian veins.

The left lumbar artery was a branch of the abdominal aorta arising at the level of superior mesenteric branch (corresponding to the level of first lumbar vertebra). It coursed laterally posterior to the left suprarenal vein (shown in the inset of figure 2) and then crossed the anterior surface of the left kidney accompanying the lumbar vein to reach the posterior abdominal wall. Vessels in case II had a smaller caliber (approx 2-3 $\mathrm{mm}$ in diameter) than the vein in case I ( $6 \mathrm{~mm}$ in diameter).

In both these cases, the right side lumbar vessels did not show similar variations. 


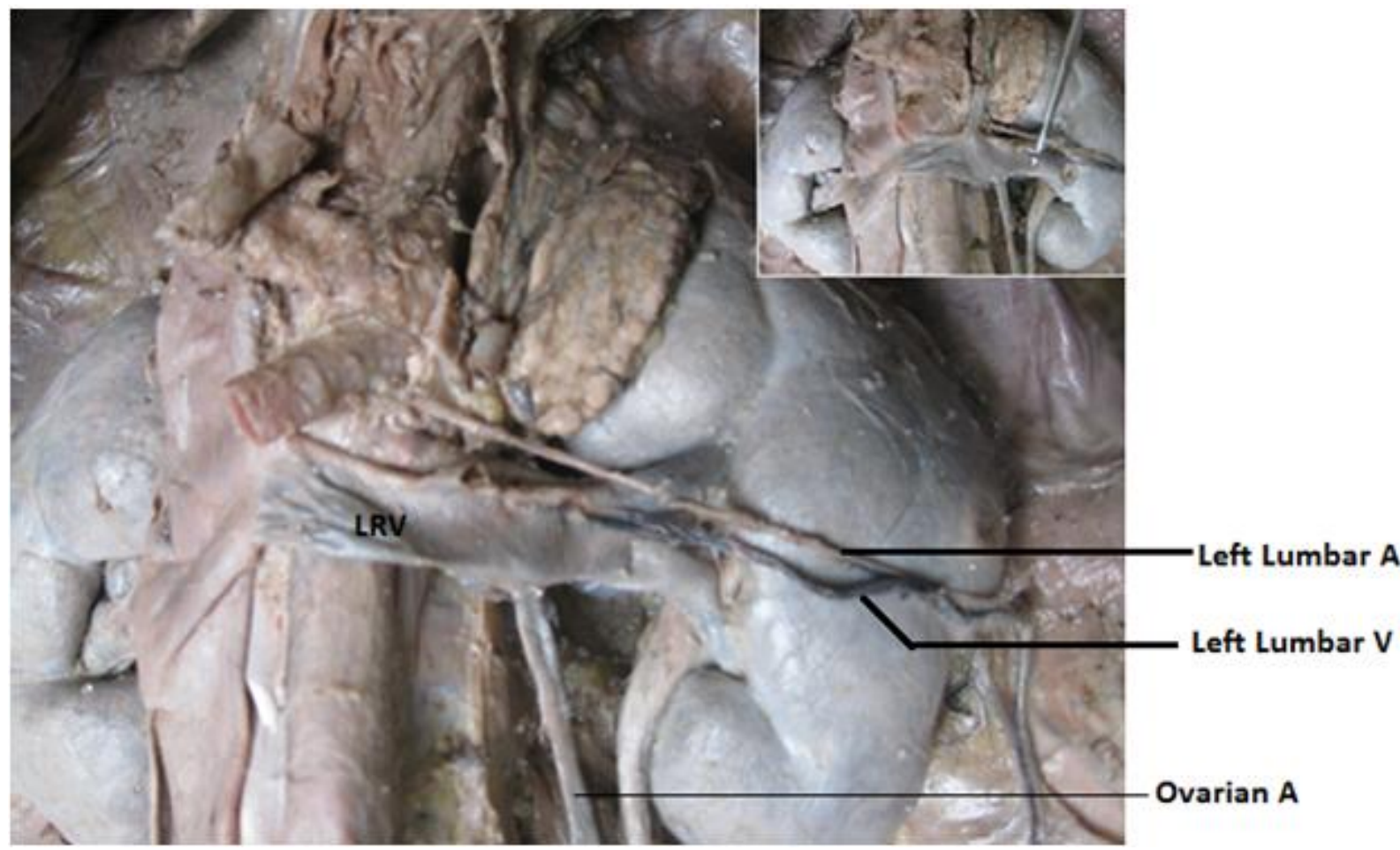

Fig 2. Figure showing a pair of lumbar vessels crossing anterior to the left kidney. Inset showing the lumbar artery posterior to the left supra renal vein

DISCUSSION: Venous variations, although frequent and often functionally insignificant, become interesting when there is an underlying developmental basis or clinical implication.

According to Edward Bass et al, anomalies of the inferior vena cava and its tributaries have been known to anatomists since 1793, when Abernethy described a congenital meso-caval shunt and azygos continuation of the IVC in a 10-month-old infant. Various anomalies of Inferior vena cava and left renal vein (e.g. left IVC, double IVC, azygos continuation of IVC, circum-aortic left renal veins and retro-aortic left renal vein) have been cited with their incidence by Edward Bass et al, Satyapal et al, Janschek et al, Singh et al, Trigaux et al, etc.

Several case reports of left renal vein variations have been reported in literature: e.g. a circum-aortic venous ring and a retro-aortic bifid left renal vein by Senecail et al, double right renal vein \& three branches of left renal vein by Malcic-Gurbuz et al, retro aortic left renal vein by Mandal et al, Dong-Soo Kyung et al and Anjamrooz et al, etc.

Left lumbar vein(s) forming a tributary (-ies) of the left renal vein has also been reported in the literature. According to Jack Baniel et al in their study on lumbar vessels, a lumbar vein entering the left renal vein was documented in $43 \%$ of cases. Raheem et al have noted lumbar vein as a posterior tributary of the left renal vein in ten of the eleven cases studied by them. Li Gang et al have given an exhaustive list of the studies showing lumbar tributaries to left renal vein; the incidence varying from $43 \%$ in the study conducted by Baniel et al to $95 \%$ of Cooley and Wukasch; their own study showing an incidence of 83.6\%.

Cases of lumbar vein forming a tributary of the renal vein have been reported by Satheesha, Jyotsna et al and Bandopadhyay et al.

In their study on the lumbar tributaries of left renal vein in 61 cases of retroperitoneoscopic left living donor nephrectomy, Li et al have found that left renal vein receives one lumbar vein as its tributary in $47 \%$ of their cases and two tributaries in $32.8 \%$ of cases. They 
have correlated the time spent by the surgeon in managing the posterior lumbar veins with the seven types of variations they have found - time spent being least when there was no lumbar tributary to the left renal vein and maximum in the presence of reno-hemiazygos-lumbar trunk draining into the left renal vein.

Although, lumbar vein(s) forming a tributary of the left renal vein has been mentioned several times in the literature as cited above, we did not come across any report of the vein being anterior to the kidney. In both our cases, the vein was initially ascending vertically along the posterior abdominal wall; it then coursed horizontally on the anterior aspect of the left kidney, finally terminating into the anterior aspect of the left renal vein.

DEVELOPMENTAL BASIS: The development of inferior vena cava and its tributaries, involves the complex sequential appearance and regression of multiple longitudinal venous channels. Variations in these veins can therefore, usually be explained on the basis of development.

During early development, veins draining the body wall open initially into the posterior cardinal veins. Later these inter-segmental veins drain into the supracardinal veins. According to Standring et al, the lower inter-segmental veins of both sides (the adult lumbar veins) drain into the supracardinal part of the inferior vena cava in adults (infra renal segment).

Jyotsna et al have suggested that the developmental basis for the lumbar vein opening into the left renal vein is due to the inter-segmental vein(s) opening into the inter-subcardinal anastomosis (the adult left renal vein) instead of the right supracardinal vein.

The vertical segment of the lumbar vein seen in our cases is situated lateral to the left kidney. Based on its lateral position, it is probably the remnant of left posterior cardinal vein and not the supra-cardinal vein as the former is ventrolateral to the latter during development. The horizontal segment crossing anterior to the kidney can be assumed to be the persisting left postsubcardinal anastomosis connecting the posterior cardinal vein with the subcardinal vein anterior to the mesonephros. Alternatively, in its final stages of ascent the metanephric kidney may have migrated in a plane more posterior to the normal, reaching between the body wall and its vessels, thus resulting in the lumbar vessels coming to lie anterior to it as seen in the case II.

CLINICAL SIGNIFICANCE: Clinically, the knowledge of such variations is of extreme importance for the surgeons dealing in this area, especially during the live donor kidney nephrectomy. For live donor nephrectomy, both open and laparoscopic methods are used, the latter being preferred due to shorter hospital stay and lesser blood loss. In laparoscopic nephrectomy, kidney can be approached using either retro-peritoneal or trans-peritoneal routes; and according to Li Gang et al although trans-peritoneal approach is method of choice in many countries, retroperitoneal method is preferred approach by urologists in China.

Traditionally, the left kidney is preferred for this procedure due to the ease of approach and greater length of the renal vein. In both our cases, we found the anomalous vessels on the left side. We believe that in trans-peritoneoscopic left live donor nephrectomy, the surgeon can visualize the anomalous lumbar vessel(s) and can hence deal with it appropriately. However, during retro-peritoneoscopic left kidney live donor nephrectomy, the presence of an anterior lumbar vein and/or a lumbar artery may be missed and can result in increased risk of hemorrhage.

According to Beckmann \& Abrams, renal phlebograms (Venograms) are commonly indicated in reno-vascular hypertension or in the cases of renal or retro-peritoneal malignancy or in thrombosis or suspected variations of renal vein. According to Linda et al and Gluecker et al, CT angiography or MRA can predict lumbar venous anatomy prior to donor nephrectomy. For an 
unsuspecting radiologist, presence of an anterior lumbar vein may pose a challenge while interpreting results.

CONCLUSION: Although lumbar tributaries to the left renal vein have been reported, presence of lumbar vein on the anterior surface of the kidney as seen in two of our cases is rare. Rarer still is the presence of a lumbar artery accompanying the lumbar vein anterior to the kidney as seen in one of these cases. Knowledge of such variations is important for both the surgeons and the radiologists dealing with this area.

\section{REFERENCES:}

1. Standring S, Borley NR, Collins P, Crossman AR, Gatzoulis MA, Healy JC, et al. Gray's Anatomy: The Anatomical Basis of Clinical Practice. 40th ed. Churchill Livingstone Elsevier; 2008: 1219-20

2. Hollinshead WH. Anatomy for surgeons: Volume 2. $2^{\text {nd }}$ ed. New York: Harper \& Row; 1971: 584-593

3. Edward Bass J, Michael D. Redwine, Larry A. Kramer, Phan T. Huynh, John H. Harris Jr. Spectrum of congenital anomalies of the inferior vena cava: Cross sectional imaging findings. Radiographics. 2000; 20:639-652

4. Satyapal KS, Kalideen JM, Haffejee AA, Singh B, Robbs JV. Left renal vein variations. Surg Radiol Anat. 1999;21:77-81

5. Janschek. Janschek EC et al. Anatomic basis of right renal vein extension for cadaveric kidney transplantation. Urology. 2004; 63:660-664

6. Singh K, Gupta V, Sharma A. An embryological correlation with the incidence of retroaortic left renal vein. J of Anat Soc of India. 2011; 60(2):190-192

7. Trigaux JP, Vandroogenbroek S, De Wispelaere JF, Lacrosse M, Jamart J. Congenital anomalies of the inferior vena cava and left renal vein: Evaluation with spiral CT. J Vasc Interv Radiol. 1998;9:339-345

8. Senecail B, Bobeuf J, Forlodou P, Nonent M. Two rare anomalies of the left renal vein. Surg Radiol Anat. 2003;25:465-467

9. Malcic-Gürbüz J, Akalin A, Gümüşcü B, Cavdar S. Clinical implications of concomitant variations of the testicular, suprarenal and renal veins: a case report. Ann Anat. 2002;184:35-39

10. Mandal S, Mandal P, Basu R. Bilateral Accessory Renal Arteries, Additional Right Renal Vein and Retroaortic Left Renal Vein- A Case Report. Int J Health Sci Res. 2013;3(2):88-93

11. Dong-Soo Kyung, Jae-Ho Lee Deuk-Yong Shin Dae-Kwang Kim and In-Jang Choi. The double retro-aortic left renal vein. Anat Cell Biol. 2012; 45(4): 282-284.

12. Anjamrooz SH, Azari H, Abedinzadeh M. Abnormal patterns of the renal veins. Anat Cell Biol. 2012;45:57-61

13. Baniel J, Foster RS, Donohue JP. Surgical anatomy of the lumbar vessels: Implications for retroperitoneal surgery. J Urol. 1995;153:1422-5

14. Raheem OA, O'Brien M, Glacken P, Mohan P, Hickey DP. A review of the anatomical variations of the posterior tributaries of the left renal vein. Irish Journal of Medical Science. 2008; 177(1): 59-62

15. Li G, Dong J, Lu JS, Zu Q, Yang SX, et al. Anatomical variation of the posterior lumbar tributaries of the left renal vein in retroperitoneoscopic left living donor nephrectomy. Int J Urol. 2011; 18(7): 503-9 
16. Satheesha NB. Abnormal course of left testicular artery in relation to an abnormal left renal vein: A case report. Kathmandu Univ Med J. 2007;5:108-9

17. Jyotsna P, Mohandas Rao KG, Somayaji SN, Ashwini LS. Multiple vascular anomalies involving testicular, suprarenal arteries and lumbar veins. N Am J Med Sci. 2012; 4(3): 154-156

18. Bandopadhyay M, Saha A. Three rare variations in the course of the gonadal artery. Int J Morphol. 2009;27:655-8

19. Linda C Chu, Sheila Sheth, Dorry L, Sergev, Robert A, Montgomery, Elliot K. Role of MDCT Angiography in selection and Presurgical planning of potential renal donors. Am J of Roentgenology. 2012;199:1035-1041

20. Beckmann Carl F, Abrams Herbert L. Renal Venography: Anatomy, technique, applications, analysis of 132 venograms, and a review of the literature. Cardiovascular \& Interventional Radiology. 1980; 3(1):45-70

21. Gluecker TM, Mayr M, Schwarz J et al. Comparison of CT angiography with MR angiography in the preoperative assessment of living kidney donors. Transplantation. 2008;86:1249-56

\section{AUTHORS:}

1. Chimmalgi $\mathrm{M}$

2. Raju G

3. Vilasini Sundaresan

4. Anil Kumar KV

5. Manoj Kumar

6. Chandrakumari K

7. Subhadra MS

8. Devi Jansirani D

\section{PARTICULARS OF CONTRIBUTORS:}

1. Professor, Department of Anatomy, Sree Gokulam Medical College \& Research Foundation, Venjaramoodu, Trivandrum.

2. Tutor, Department of Anatomy, Sree Gokulam Medical College \& Research Foundation, Venjaramoodu, Trivandrum.

3. Professor, Department of Anatomy, Sree Gokulam Medical College \& Research Foundation, Venjaramoodu, Trivandrum.

4. Assistant Professor, Department of Anatomy, Sree Gokulam Medical College \& Research Foundation, Venjaramoodu, Trivandrum.

5. Associate Professor, Department of Surgery, Armed Forces Medical College, Pune.
6. Professor, Department of Anatomy, Sree Gokulam Medical College \& Research Foundation, Venjaramoodu, Trivandrum.

7. Professor, Department of Anatomy, Sree Gokulam Medical College \& Research Foundation, Venjaramoodu, Trivandrum.

8. Assistant Professor, Department of Anatomy, Sree Gokulam Medical College \& Research Foundation, Venjaramoodu, Trivandrum.

\section{NAME ADRRESS EMAIL ID OF THE CORRESPONDING AUTHOR:}

Dr. Mamata Chimmalgi,

Professor, Department of Anatomy,

Sree Gokulam Medical College \& Research

Foundation, Venjaramoodu,

Trivandrum - 695607.

Email-mamatachimmalgi@gmail.com

Date of Submission: 02/07/2013.

Date of Peer Review: 03/07/2013.

Date of Acceptance: 18/07/2013.

Date of Publishing: 19/07/2013 